\title{
Contribuições da fenomenologia para os estudos organizacionais
}

\author{
Contributions of phenomenology to organizational studies
}

\author{
Diego Luiz Teixeira Boava ${ }^{1}$ \\ Fernanda Maria Felício Macedo ${ }^{2}$
}

\begin{abstract}
Resumo
Este artigo discute elementos que viabilizam outra possibilidade de compreensão dos fenômenos administrativos, através de uma descrição propedêutica da fenomenologia e do método fenomenológico. Objetiva-se, assim, apresentar as principais contribuições e possibilidades da fenomenologia para os estudos organizacionais. Aprofunda-se em considerações sobre a fenomenologia em geral e os diversos tipos de métodos fenomenológicos em particular, buscando esclarecer sobre a filosofia existente nesses temas, para auxiliar os pesquisadores em seu labor diário. Discorre-se também sobre a redução, que na verdade são duas: a eidética e a fenomenológica. Tais reduções são vitais para retirar o homem de sua atitude natural. Outro assunto aqui abordado é a transposição do método fenomenológico do campo filosófico para o campo da pesquisa empírica. Diante dessa contextualização, tem-se o último assunto a ser abordado, que vai diretamente ao encontro do objetivo desta pesquisa, discutindo-se a utilização da fenomenologia no contexto da administração. A título de ilustração, são apresentados diversos estudos que têm a fenomenologia como tema, bem como um método fenomenológico empírico específico da área de estudos organizacionais. Dessa maneira, a temática neste artigo é situada, sendo preciso agora avançar em direção a outras possibilidades.
\end{abstract}

Palavras-chave: Fenomenologia. Método fenomenológico. Estudos organizacionais.

\begin{abstract}
This study discusses the elements that enable another way of understanding administrative phenomena through a description workup of phenomenology and the phenomenological method. Thus, the object is to present the main contributions and possibilities of phenomenology to organizational studies. It analyzes in detail considerations of phenomenology in general and the various types of specific phenomenological methods, seeking to clarify the philosophy that exists in these themes to assist researchers in their daily work. It also discusses phenomenological and eidetic reduction. These reductions are vital for removing man from his natural attitude. Another issue the article broaches is the implementation of the method of phenomenological philosophy into the realm of empirical research. In this context
\end{abstract}

Artigo submetido em 23 de junho de 2010 e aceito para publicação em 26 de novembro de 2010.

Mestre em Administração pela Universidade Estadual de Londrina; Professor Assistente da Universidade Federal de Ouro Preto; Instituto de Ciências Sociais Aplicadas - UFOP. Endereço: Rua do Catete, 166, Centro, Mariana, MG, CEP 35420-000. E-mail: profboava@yahoo.com.br

2 Mestre em Administração pela Universidade Estadual de Londrina; Professora Assistente da Universidade Federal de Ouro Preto; Instituto de Ciências Sociais Aplicadas - UFOP. Endereço: Rua do Catete, 166, Centro, Mariana, MG, CEP 35420-000. E-mail: profboava@yahoo.com.br 
comes the latest topic to be addressed, which is in line with the aims of this study, discussing the use of phenomenology in the context of management. To illustrate it, several studies are presented on phenomenology and a specific empiric phenomenological method in the field of organizational studies. Thus, the theme of this article has been pinpointed, and it is now necessary to move on to other possibilities.

Keywords: Phenomenology. Phenomenological method. Organizational studies.

\section{Introdução}

Neste artigo pretende-se discutir, fenomenologicamente, as contribuições oferecidas pela fenomenologia para os estudos organizacionais. Dessa análise, poderão surgir, ainda, novas possibilidades de investigação organizacional empregando a fenomenologia, capazes de oferecer uma visão distinta dos fenômenos administrativos, indo além da tradicional concepção originada pelo emprego do funcionalismo. Para tal, farse-á uma explicitação propedêutica do que consiste o movimento fenomenológico, desde suas origens filosóficas até a transposição de seus conceitos para as chamadas ciências humanas, analisando-se as aplicações em administração. Busca-se discutir a filosofia fenomenológica, demonstrando suas implicações para o conhecimento em geral e para a própria ciência.

Trata-se de uma tentativa de aproximação entre dois campos completamente distintos: a administração (predominantemente funcionalista-positivista) e a filosofia (especulativa). Consequentemente, as análises em tela poderão auxiliar os teóricos organizacionais a descortinar outras possibilidades de estudo, notadamente, de cunho filosófico. Intenta-se evitar, decididamente, a perda de rigor que habitualmente ocorre ao se fazer a transmutação da fenomenologia do campo filosófico para o campo científico. Para isso, buscar-se-á circunscrever o máximo possível a discussão ao âmbito epistêmico-ontológico (filosófico).

Portanto, pode-se dizer que este estudo objetiva apresentar as principais contribuições e possibilidades da fenomenologia para os estudos organizacionais, em termos epistemológicos. Para isso, é traçado um panorama da investigação fenomenológica considerando-se suas diferentes abordagens originadas da transposição do uso filosófico para o das ciências empíricas. Na sequência, são apresentados diversos estudos organizacionais que têm a fenomenologia como tema, bem como um método fenomenológico empírico específico da área de estudos organizacionais.

\section{Sobre a Fenomenologia como Área da Filosofia: Origens, Desdobramentos, Principais Filósofos e Tendências Futuras}

Fenomenologia significa discurso sobre aquilo que se mostra como é. É formada pelos termos gregos phainomenon ( mostra. Logos é o estudo, a razão, o discurso.

Ao longo da história da filosofia, vários filósofos usaram o termo em diferentes sentidos. Lambert (1764) é tradicionalmente considerado o primeiro a usar a palavra fenomenologia, na quarta parte da obra Neues organon..., intitulada em português 'Fenomenologia ou aparência ilusória e suas variedades', que traz todo o fundamento do saber empírico, cabendo à fenomenologia distinguir entre a aparência e a verdade. Porém, antes dele, Oetinger (1762) também fez uso do termo phänomenologie, em Die Philosophie der Alten wiederkommend in der güldenen Zeit (A filosofia dos antigos retomada na era de ouro), efetuando estudos sobre o sistema divino de relações. 
Outro filósofo que emprega o termo é Kant (1786, 1999a, 1999b), a partir de Lambert (1764). Ao enviar a Lambert seu trabalho De mundi sensibilis atque intelligibilis forma et principiis, Kant (1999a) discute uma disciplina propedêutica que deve anteceder à metafísica, chamada de phaenomenologia generalis. Em outra carta, a Marcus Herz, Kant (1999b) fala sobre A fenomenologia em geral, que deveria ser parte de um novo estudo então em gestação, depois designado Kritik der reinen vernunft (Crítica da razão pura), escrito em 1781. Entretanto, tal intenção não foi concretizada posteriormente. Não obstante, Kant (1786) acabou retomando o emprego do vocábulo fenomenologia no quarto capítulo do livro Metaphysische anfangsgründe der naturwissenschaft, intitulado 'Fundações metafísicas da fenomenologia'.

Fichte (2005), discípulo de Kant, também faz uso do termo fenomenologia em Wissenschaftslehre (Doutrina da ciência), empregando o termo para se referir às aparências. Hegel (1807) é outro filósofo que faz uso do vocábulo. Em seu livro Phänomenologie des geistes (Fenomenologia do espírito), estabelece a dialética e busca criar um sistema filosófico.

Esses foram os filósofos mais proeminentes que usaram o termo fenomenologia. Porém, aquele que consagrou o uso do termo e criou uma nova escola filosófica foi Edmund Husserl.

Na virada do século XIX para o século XX, Husserl (1999a, 1999b) publicou a obra Logische untersuchungen (Investigações lógicas), trazendo novos significados para uma antiga palavra, com impactos para a filosofia e para a ciência. Nesse trabalho, Husserl (1999a, 1999b) causou grande polêmica ao atacar o psicologismo na lógica, abordagem centrada no emocional humano, minimizando sua consciência racional, ao propor uma reorientação do pensamento puro. A intenção foi estabelecer uma base epistemológica para a filosofia, que a convertesse numa ciência do rigor. Para isso, criou o chamado método fenomenológico. Assim, disse que a consciência é a condição sine qua non de qualquer conhecimento e que é intencional (toda consciência é consciência de algo).

Para o autor, o trabalho do filósofo é a superação das atitudes naturalistas e psicologistas, por meio da apreensão das essências das coisas, que podem ser reconhecidas por meio de regras sistemáticas definidoras da variação dos objetos na imaginação.

Destarte, a fenomenologia consiste em uma tentativa elucubradora para resgatar o contato original com o objeto, que se perdeu em especulações metafísicas abstratas ou reduções matemáticas. Sempre há uma volta às origens.

Ao ir às coisas mesmas, à procura de exprimir aquilo que é dado diretamente na consciência, a fenomenologia descreve e analisa o significado e a relevância da experiência humana. A consciência, aqui, difere daquela propugnada pelos kantianos e neokantianos. Para estes, a referida consciência era assimiladora, ao passo que em Husserl (1999a, 1999b) a consciencia intencional é como um farol que projeta sobre as aparências, aspectos ou aquilo que se apresenta à mesma (MORA, 1963, p.56).

Abbagnano (1993, p.76), ao analisar a história da filosofia, diz que o trabalho de Husserl fundamenta-se nos seguintes pontos:

- é uma ciência teorética (contemplativa) e rigorosa, isto é, fundamentada, no sentido de ser dotada de fundamentos absolutos;

- é uma ciência intuitiva, porque tenta apreender essências que se apresentam à razão de uma forma análoga àquela em que as coisas se apresentam à percepção sensível. Esse aspecto da filosofia reflete o caráter apofântico da razão (levando em conta a possibilidade de qualquer enunciado ser considerado verdadeiro ou falso, em função de descrever corretamente, ou não, o mundo real); 
- é uma ciência não objetiva, e por isso completamente diferente das outras ciências particulares, que são ciências dos fatos ou das realidades (físicas ou psíquicas), enquanto ela prescinde de qualquer fato ou realidade, preocupando-se apenas com essências;

- é uma ciência das origens e dos primeiros princípios, dado que a consciência contém o sentido de todos os possíveis modos como as coisas podem ser dadas ou constituídas;

- é uma ciência da subjetividade, porque a análise da consciência se dirige para o eu como sujeito ou polo unificador de todas as intencionalidades constitutivas; e

- é uma ciência impessoal, porque os seus colaboradores não têm necessidade de prudência, mas de dotes teoréticos.

Como observa o autor, esses aspectos definem a fenomenologia entendida por Husserl, mas não o conjunto do movimento fenomenólogico, que possui diversos autores e tendências. Não obstante, antes de se discutir as tendências, é importante compreender o significado do termo fenômeno. Tal palavra representa aquilo que se investiga por meio da intuição, derivando-se da consciência intencional.

A consciência não opera no vazio, daí, para haver objeto, deve haver um sujeito e vice-versa. Assim, noesis é o nome dado ao ato de perceber (o cogitatio). Noema, por sua vez, representa o que é percebido (o cogitatum). Logo, o que se investiga é um fenômeno de consciência (noema). O fundamental na fenomenologia é a busca dos significados das experiências que chegam à consciência.

Em relação ao assunto, Husserl (1988) esclarece que:

[...] chamaremos de fenômeno tudo aquilo que é vivência, na unidade de vivência de um eu: a fenomenologia é, por conseguinte, a doutrina das vivências gerais, abrangendo também a doutrina de todos os dados, não só os genuínos, mas também os intencionais, que podem ser evidenciados nas vivências. (Ibidem, p.176)

Prosseguindo com a discussão, destaca-se que desde seu advento a fenomenologia evoluiu e se desenvolveu de diferentes formas.

Embree et al (1997, p.1-6), na obra Encyclopedia of phenomenology, apresenta as quatro grandes tendências e períodos dentro do movimento fenomenológico, observando que qualquer tentativa de resumir a riqueza de pontos de vista que se enquadram nessas posições, certamente, seria inadequada:

1. fenomenologia realista - busca as essências universais de vários tipos de assuntos: ciências formais, linguagem, percepção e representação (memória, empatia, confiança, imaginação), incluindo estudos de gênero, direito, antropologia filosófica, religião, valor, estética, arquitetura, música e cinema. Principais nomes: Johanes Daubert, Adolf Reinch, Alexander Pfander, Herbert Spiegelberg, Karl Schuhmann, Barry Smith, Max Scheler, Edith Stein, Moritz Geiger e Roman Ingarden;

2. fenomenologia constitutiva - a investigação fenomenológica inclui a filosofia das ciências naturais. Aplicação das chamadas redução fenomenológica e redução eidética, visando suspender a aceitação do estado pré-dado da vida consciente como algo que existe no mundo. Surgiu com a obra 'Ideias para uma fenomenologia pura e para uma filosofia fenomenológica...', de 1913 (HUSSERL, 2006). Principais nomes: Alfred Schütz, Oskar Becker, Aron Gurwitch, Elisabeth Stroker, Gaston Berger, Jean Cavailles, Eugen Fink, Ludwig Landgrebe, Jitendra Mohanty, Thomas Seebohm, Robert Sokolowski;

3. fenomenologia existencial - discussões sobre a ação, conflito, desejo, finitude, opressão, morte, teoria política, problemática da etnicidade, gênero, idade, percepção, corpo vivido, liberdade e 
literatura. Desenvolve-se a partir da obra de Heidegger 'Ser e tempo', de 1927 (HEIDEGGER, 1999). Principais nomes: Martin Heidegger, Jean-Paul Sartre, Simone de Beauvoir, Maurice Merleau-Ponty, Hannah Arendt, Emmanuel Levinas, Gabriel Marcel, Alexandre Kojeve, Dean Wahl, John Compton, Henry Michel, Natanson Maurice e Bernhard Waldenfels;

4. fenomenologia hermenêutica - deriva de 'Ser e tempo', considerando que toda a existência humana é interpretativa, não havendo acesso a nada. Somente é possível compreender o fenômeno como ele aparece dentro do contexto. A temática dessa tendência filosófica inclui todas as que já estavam nas fases anteriores, diferindo somente na ênfase dada à hermenêutica, ou método de interpretação. Inclui estética, ética, história, línguas, direito, literatura, percepção, política, religião, filosofia da natureza (especialmente as ciências humanas) etc. Principais nomes: Martin Heidegger, HansGeorg Gadamer, Paul Ricoeur, Patrick Heelan, Graeme Nicholson, Joseph Kockelmans, Calvin Schrag, Gianna Vattimo, Carlo Sini, Don Ihde.

Convém observar que frequentemente se faz referência a outra tendência, chamada de fenomenologia descritiva. Essa tendência, que deriva basicamente das 'Investigações lógicas 1' e 2 de Husserl (1999a, 1999b), refere-se a um tipo de abordagem reflexiva, evidencial e eideticamente descritiva, tanto dos encontros entre seres como dos estabelecidos entre ser e objeto. Trata-se da inauguração da fenomenologia, quando são abordados problemas referentes à lógica, à linguagem, à percepção e a vários tipos de representação (como por exemplo, expectativa, imaginação e memória). Essa primeira fase da fenomenologia é como uma matriz para as outras quatro subsequentes.

As fenomenologias realista e constitutiva desenvolveram-se na Alemanha por volta da I Guerra Mundial, ao passo que a fenomenologia existencial teve lugar na França, entre as décadas de 1930 e de 1960. Por sua vez, a fenomenologia hermenêutica foi influente nos EUA a partir dos anos 1970. Com o colapso da União Soviética, um contato maior com o Leste Europeu se estabeleceu, proporcionando um rico relacionamento entre os pesquisadores. O mesmo ocorre na América Latina e na Ásia, que demonstram um crescente interesse em relação à fenomenologia, o que faz supor que o período da fenomenologia americana esteja diminuindo, enquanto um quinto período começa.

Nesse sentido, Embree $(2001,2005)$ discute a emergência da quinta etapa desse desenvolvimento, que seria a fenomenologia cultural ou fenomenologia da vida mundana, caracterizada pelo foco da investigação e pela visão ampliada, em relação a temas do cotidiano.

Os quatro estágios de desenvolvimento da fenomenologia (ou seis, caso se considere a matriz descritiva e a nova etapa cultural) exploraram e transformaram os conceitos iniciais. O que todos têm em comum, entre outros fatores, é a aplicação do método fenomenológico na investigação, que será visto a seguir.

\section{Considerações acerca do Método Fenomenológico no Domínio Filosófico: As Principais Etapas e os Tipos de Redução}

Quando se pensa em método fenomenológico, aparentemente se quer dizer que algo seja parecido com um conjunto sistemático de proposições aplicáveis a um determinado problema (a exemplo das ciências). Porém, não existe um ou o método, mas, sim, variações. Nesse sentido, Spiegelberg (1982, p.681-714) relaciona o passo-a-passo dos métodos adotados por vários fenomenólogos:

\section{Investigar os fenômenos particulares}

É o processo de intuir, analisar e descrever. Intuir significa o esforço de se concentrar sobre o objeto, evitando que se perca a visão crítica. Analisar é delimitar os elementos e a estrutura do fenômeno apreendido 
por intuição. Não se trata de separá-los, mas sim distinguir os constituintes do fenômeno, assim como a exploração de suas relações e de suas conexões com outros fenômenos. Descrever consiste na classificação dos fenômenos. A descrição por negação é um modo simples de indicar a unicidade e a irredutibilidade do fenômeno.

\section{Investigar as essências gerais}

Trata-se da intuição edidética. Essa etapa vai dos casos particulares de fenômenos às essências gerais. Buscase ver através de ou descobrir a essência do fenômeno, pois não há intuição da essência adequada sem a intuição antecedente. Para ter a essência geral deve-se considerar os particulares como referência. Tais indicações podem ser dadas quer na percepção, quer na imaginação ou em ambos. A imaginação fornece a estrutura noemática. A partir da identificação do princípio que norteia a intuição sobre o que é e o que não é possível imaginar como percepções, enxerga-se o que é essencial para a percepção. A variação imaginativa livre é usada para distinguir a essência de um fenômeno do fenômeno original. Esta etapa envolve novamente uma intuição, uma análise e uma descrição. Não se descreve o objeto, mas o que é possivel se enxergar como objeto.

\section{Captar as relações essenciais entre as essências}

Há duas formas de relações essenciais: a relação entre as partes de uma única coisa e a relação entre as coisas separadas, mas unidas. Trata-se da descoberta de certas relações essenciais ou conexões referentes a tais essências. Também se usa a chamada variação imaginativa livre, que consiste em abandonar alguns componentes e substituí-los por outros.

\section{Observar os modos de aparição}

A ênfase não é sobre o que aparece na consciência, mas como objetos aparecem na consciência. Há três sentidos de aparência: a) o lado ou aspecto de um objeto, a partir do todo; b) o fato de que a aparência do objeto pode estar deformada, o que se chama de perspectiva (explicando assim como um objeto pode ser diferente para pessoas diferentes em diferentes momentos; c) a possibilidade dos níveis de clareza, grau ou nitidez poderem ser distintos, o que se aplica principalmente a áreas periféricas do campo fenomenal.

\section{Explorar a constituição dos fenômenos na consciência}

Busca-se aqui determinar o caminho seguido para que o fenômeno se estabeleça e tome forma na consciência. Assim, torna-se possível determinar a estrutura típica de sua constituição na consciência, por meio de uma análise da sequência de suas etapas essenciais. A exploração da constituição do fenômeno revela não só os aspectos da consciência, mas também aspectos do fenômeno.

\section{Suspender a crença no fenômeno}

É a chamada redução, epoché, colocação entre parentêses. Trata-se de suspender momentâneamente o juízo sobre a existência ou não existência do fenômeno (corresponde à suspensão momentânea da faculdade de avaliar), para verificação desse fenômeno numa nova perspectiva. Assume-se uma atitude neutra, visando refletir e questionar, de forma a tornar possível apreender novo sentido sobre fatos que não tinham sido vistos e observados anteriormente. Busca-se, assim, preservar o conteúdo e a forma do fenômeno do modo mais completo e puro possível. 


\section{Interpretar as significações ocultas}

Há um avanço em relação aos trabalhos de Husserl. Nessa etapa, procura-se descobrir os significados que não se manifestam na intuição, análise e descrição. Observa-se que todo estudo de estruturas intencionais consiste principalmente em uma análise interpretativa e na descrição dos significados dos atos conscientes.

As três primeiras etapas são cumpridas por praticamente todos os fenomenólogos. Quanto às demais, depende da orientação filosófica adotada. A sexta etapa refere-se à redução fenomenológica, enquanto a sétima é cumprida pelos adeptos da fenomenologia hermenêutica.

Husserl (1990) discute sobre o assunto:

É este necessariamente seu caráter; a fenomenologia quer ser ciência e método, a fim de elucidar possibilidades, possibilidades de conhecimento, possibilidades de valoração, e as elucidar a partir do seu fundamento essencial; são possibilidades universalmente em questão e, portanto, as investigações fenomenológicas são investigações universais de essências. (Ibidem, p.79)

Assim, o método fenomenológico não pretende ser empírico, indutivo ou dedutivo, mas descritivo. Sua finalidade é a descrição do fenômeno, tal como ele se apresenta, sem reduzi-lo a algo que não apareça. Epistemologicamente, opõe-se à visão de sujeito e objeto isolados, passando a considerá-los como correlacionados, já que a consciência é sempre intencional.

O homem é considerado um doador de sentido ao mundo, e a origem de todas as afirmações racionais é a consciência doadora originária, que está centrada no fenômeno, ou seja, naquilo que é visado pela consciência. Logo, o método centra-se no homem, especificamente, na análise do significado e relevância da experiência humana. O ponto inicial da investigação fenomenológica é a compreensão do viver.

Essa análise é efetuada conforme as etapas descritas anteriormente e implica abordar o fenômeno, para que este chegue à consciência. Denomina-se fenômeno aquilo que de fato é apresentado à consciência humana e que pode ser apreendido, pois toda consciência é consciência de algo. Para diminuir ou acabar com o subjetivismo (que poderia comprometer a confiabilidade dos estudos baseados no método fenomenológico), existe a chamada redução, que é a busca do fenômeno livre de traços pessoais e culturais, que leva à essência.

Basicamente, há duas reduções: a eidética e a fenomenológica (ou transcendental). Quanto à redução eidética, Bochenski (1971, p.51-58) afirma que o pesquisador deve efetuá-la da seguinte maneira:

1. eliminação no grau possível do subjetivo - assumir atitude objetiva diante do dado. A volta às coisas mesmas exige não só a exclusão das atitudes subjetivas, mas também a de toda objetividade. Deve-se ver somente o que é dado, o fenômeno, e nada mais;

2. exclusão do teórico - eliminação momentânea de todas as descobertas, hipóteses, teorias ou de outro conhecimento prévio. No curso da investigação fenomenológica não se pode fazer qualquer uso de métodos indiretos de conhecimento;

3. suspensão da tradição - exclusão das tradições das ciências e das autoridades humanas. Somente as próprias coisas, como fenômenos que surgem diante dos olhos do pesquisador, devem ser observadas e nada mais;

4. ver todo o dado e não somente alguns aspectos do objeto - isso em si é uma clara e simples regra. Foi formulada de modo claro e aplicada conscientemente, pois o homem tem uma forte tendência a 
ver apenas determinados aspectos do objeto, em vez dos dados. Assim, a primeira tarefa da investigação fenomenológica é revelar os fenômenos negligenciados;

5. descrever o objeto, analisando suas partes - isso significa que o fenômeno deve ser descrito e analisado, pois cada fenômeno é infinitamente complexo. A visão geral é mais adequada para entender as relações mútuas entre os fenômenos.

O objetivo dessa redução é atingir a essência, o eidos. Então, a realidade, em função da livre consideração de todas as possibilidades que a razão descobre, perde as características individuais e se revela uma essência constante e invariável.

Neste sentido, Giles (1989) observou que:

O impulso de investigação fenomenológica deve partir não dos filósofos e, sim, das próprias coisas. Não sou eu, nem as minhas convicções e, sim, as próprias coisas, como estas se revelam na sua pureza irrefutável, que têm de se impor para dar testemunho de verdade. (Ibidem, p.59)

Por sua vez, a redução fenomenológica visa limitar o conhecimento ao fenômeno da experiência de consciência. Para isso, procura desconsiderar o mundo real, numa espécie de suspensão do juízo; em outras palavras, o põe entre parênteses.

Mas o que significa isso? O homem se encontra no mundo, foi lançado nesse mundo e nele vive. Chama-se atitude natural os termos e o modo pelo qual esse homem percebe, interpreta e age no mundo em que vive. Trata-se de um modo ingênuo de existir que faz com que a humanidade acredite que as coisas são como se mostram. Não há dúvidas em relação a isso. Assim, há os padrões de comportamento e as certezas das coisas.

Desse modo, a redução fenomenológica leva o investigador a romper com a crença no mundo exterior, seja da forma como ela é vista pelos seres humanos no dia a dia, seja da forma como ela vista pelos teóricos, filósofos ou cientistas. Isto é, ocorre uma ruptura com a visão de mundo estereotipada, sendo possível então atingir-se a autonomia em relação ao mundo e à consciência que dele se tenha.

Feitas essas colocações, podemos analisar as diferentes maneiras como a ciência apropriou-se da fenomenologia, conforme exposto a seguir:

\section{Sobre a Transferência do Método Fenomenológico do Campo Estritamente Filosófico para o das Ciências Empíricas: Tipos e Usos}

No intuito de aplicar a fenomenologia às ciências empíricas, diversos pesquisadores de diferentes disciplinas fizeram adaptações e elaboraram um conjunto de procedimentos que são utilizados em variadas pesquisas, particularmente, nas áreas da saúde e psicologia.

O objetivo dessas adaptações é captar o significado e a relevância da experiência humana sobre o que se quer pesquisar (por meio de entrevistas), pois o homem possui significados que lhe são inerentes, aos quais se pode chegar através da fenomenologia.

Demonstrar-se-á quais os principais métodos empregados pelos cientistas sociais no estudo desses fenômenos humanos. 
Um dos pioneiros na transposição do método fenomenológico filosófico para as ciências empíricas foi Van Kaam $(1959,1966)$. A adaptação mais usada do método de Van Kaam (1966, p.314-16) envolve seis etapas:

1. classificação dos dados em categorias - consiste na elaboração de um conjunto de expressões relevantes (oriundas de entrevistas), classificando-as em categorias, a partir do que os próprios sujeitos estão falando;

2. redução - trata-se de transformar os dados brutos advindos da fala do sujeito pesquisado em uma linguagem do pesquisador; ou seja, busca-se precisar os termos;

3. eliminação de elementos - esta terceira etapa consiste na eliminação dos elementos que não sejam inerentes ao fenômeno (isto é, possíveis partes de uma situação específica não relacionada ao que se pretende investigar);

4. identificação dos constituintes descritivos - as três etapas anteriores oferecem um conjunto de informações que se tornam a primeira verificação dos constituintes descritivos da experiência;

5. aplicação - esta é a etapa mais trabalhosa.A descrição dos constituintes da etapa 4 é aplicada aleatoriamente a determinados protocolos selecionados (ou seja, a certas entrevistas). A descrição é testada para verificar se ela abarca mais componentes dos que os necessários à compreensão do fenômeno investigado. É verificado ainda se alguns dos protocolos contêm elementos inerentes ao fenômeno, mas que tenham sido esquecidos na descrição dos constituintes descritivos. Em tais situações, a descrição dos constituintes é revista, para se reduzir ou ampliar seus elementos;

6. identificação final - uma vez que as cinco etapas anteriores sejam concluídas com sucesso, a descrição dos constituintes pode ser considerada válida e efetiva em relação ao fenômeno investigado, levando-se em conta o conjunto de indivíduos pesquisados.

Tal método é utilizado predominantemente em pesquisas psicológicas, em relação a sentimentos, experiências humanas e a outros aspectos relativos a essa ciência.

Moustakas (1994, p.120-21) modifica e amplia o método de Van Kaam (1966), que passa a se configurar da seguinte maneira:

1. listagem e agrupamento preliminar - lista de todas as expressões relevantes para a experiência (horizontalização);

2. redução e eliminação - busca-se determinar os componentes invariantes. Cada expressão é testada, observando-se dois requisitos: a) Será que ela contém um momento da experiência que seja um componente necessário e suficiente para compreendê-la? b) É possível rotulá-la abstratamente? Se assim for, é um horizonte da experiência. Expressões que não cumpram os requisitos anteriormente referidos são eliminadas. Sobreposição de expressões, repetições e expressões vagas também são eliminadas ou apresentadas de forma mais exata, em termos descritivos. Os horizontes que permanecem são os constituintes invariáveis da experiência;

3. agrupar e tematizar os constituintes invariantes - agrupar os constituintes invariáveis da experiência relacionados a um rótulo temático. O agrupamento e os rótulos constituintes são os temas centrais da experiência;

4. identificação final dos constituintes invariantes e temas por aplicação - a validação dessa etapa se dá pela verificação dos constituintes invariantes e seus temas com os registros efetuados anteriormente. $\mathrm{O}$ que se busca é esclarecer: a) se estão explicitamente expressos na transcrição da entrevista; b) se são compatíveis com eles, se não explicitamente expressos; c) se, caso não sejam explícitos ou compatíveis, seriam irrelevantes para a experiência do participante, devendo ser excluídos; 
5. descrição textual individual - são usados os constituintes invariantes válidos e temas para cada descrição da experiência. Incluem-se exemplos integrais a partir da transcrição das entrevistas;

6. descrição estrutural individual - baseia-se na variação imaginativa livre e em cada descrição da experiência, a partir da descrição textual individual;

7. descrição textual estrutural - têm-se os significados e essências da experiência, incorporando-se os constituintes invariantes e temas. A partir das descrições individuais (textual e estrutural), é feita uma descrição (síntese) que represente o grupo como um todo.

Outro método frequentemente utilizado em pesquisas empíricas é o de Colaizzi (1978, p. 48-71), que se estrutura da seguinte forma:

1. adquirir o sentido de cada transcrição - é feita uma leitura de cada relato para se ter uma visão do conjunto;

2. extrair demonstrações significativas - buscam-se assertivas significativas em relação ao fenômeno pesquisado;

3. formulação de significados - são extraídos significados das colocações dos sujeitos;

4. organização dos significados formulados em conjuntos de temas - são elaborados conjuntos de temas oriundos da etapa de formulação de significados;

5. descrição exaustiva do fenômeno investigado - refere-se à descrição exaustiva dos conteúdos apreendidos nas etapas anteriores;

6. descrição da estrutura fundamental do fenômeno - a descrição exaustiva do fenômeno é transformada numa descrição fundamental do que está sendo pesquisado;

7. retorno aos participantes - consiste em se verificar, com os sujeitos de pesquisa, os resultados obtidos.

Van Manen (1990, p.30-31) elabora outra variante, que se configura conforme explicação a seguir:

1. voltar-se para o fenômeno de interesse - busca-se atribuir sentido a algum aspecto da experiência humana, explorando um aspecto da existência;

2. investigação da experiência como se vive - exploração ativa do tipo de experiência vivida em todas as suas modalidades e aspectos;

3. reflexão sobre os temas essenciais que caracterizam o fenômeno - pretende-se entender o significado de um fenômeno em termos de unidades, estruturas ou temas de significados, visando à distinção entre aparência e essência;

4. descrição do fenômeno - aplicação da linguagem e da reflexão a um aspecto da experiência vivida, por meio da descrição do fenômeno, registrando-a no papel;

5. manter uma relação forte e orientada para o fenômeno - aqui o objetivo é manter o foco no que se está pesquisando, evitando que opiniões preconcebidas, concepções, lembranças e experiências do investigador atrapalhem;

6. equilibrar o contexto da pesquisa - consideram-se as partes e o todo do fenômeno, ou seja, a interpretação, feita mediante a análise do que se está estudando e escrevendo sobre tal fenômeno.

O método mais utilizado nas ciências humanas, no entanto, é o de Giorgi (1985, p. 10-19), que apresenta as seguintes etapas: 
1. sentido do todo - apreendido a partir da simples leitura do texto, conforme a habilidade do sujeito de entender a linguagem;

2. discriminação das unidades de sentido - feita considerando-se que é impossível analisar um texto inteiro ao mesmo tempo e que, portanto, este dever ser separado em unidades manejáveis. Estas são analisadas de acordo com o interesse da pesquisa (caráter psicológico, econômico, sociológico, organizacional etc.);

3. transformação das expressões da linguagem do sujeito numa linguagem que enfatiza o fenômeno investigado - a intenção é chegar a uma categoria geral, partindo de expressões concretas. $\mathrm{O}$ fundamental é determinar precisamente a linguagem, padronizar, com o intuito de torná-la mais clara numa perspectiva fenomenológica;

4. resultado das unidades de sentido transformadas em colocações - o objetivo é sintetizar, integrar e descrever as descobertas das unidades mais significativas.

Como observado, os métodos apresentados não fazem significativas menções a aspectos filosóficos. Isso é importante, pois muitos pesquisadores das ciências humanas podem ser levados a desconsiderar em suas análises o arcabouço fillosófico existente por trás do método que empregam.

Embree (2001), por exemplo, diz que certas pesquisas chamadas de qualitativas ou interpretativas incluem o que se poderia chamar de refugiados do positivismo, e que a filosofia poderia ser útil para auxiliar nessa questão.

Von Zuben (1989) também observa esse problema:

Há que se evitar, no entanto, vieses e reducionismo; entende-se, muitas vezes, aplicação da fenomenologia ou do método fenomenológico como uma espécie de prestação de serviços especializados de um quadro conceitual esotérico. Por alguma razão nem sempre claramente identificada... o cientista (social em particular) entra em contato com a "moda", ou a "onda", ou o "mito", da fenomenologia em busca de subsídios para sua pesquisa. (Ibidem, p.155-156)

Isso, porém, não significa que os criadores de tais métodos não tenham conhecimento filosófico sobre fenomenologia. O problema são os pesquisadores e o uso que fazem de tal metodologia.

Para ilustrar, podem ser citados Giorgi (1978, 1985, 2005, 2008) e Giorgi e Giorgi (2003), que, reiteradas vezes, fundamentam seus métodos filosoficamente e adotam a redução de forma clara em seus escritos.

Nesse sentido, Husserl (1990, p.47) discute sobre apropriações na ciência:

$\mathrm{Na}$ esfera natural da investigação, uma ciência pode, sem mais, edificar-se sobre outra e uma pode servir à outra de modelo metódico, se bem que só em certa medida, determinada e definida pela natureza do respectivo campo de investigação.

A questão central está relacionada ao conhecimento que o pesquisador empírico possui sobre a filosofia fenomenológica e ao ponto até o qual seu trabalho pode ser chamado de fenomenológico. Isso é possível saber mediante a verificação dos processos pelos quais ele chegou aos resultados e se atingiu ou não a essência do fenômeno pesquisado, por exemplo.

Assim, Giorgi (2008, p.407) diz que para uma pesquisa ser qualificada de fenomenológica deve demonstrar: 
1. conhecimento da natureza intencional da consciência;

2. utilização da redução em sua acepção exata;

3. práticas descritivas minuciosas;

4. uma busca de estruturas ou essências próprias à disciplina, por meio de variações livres e imaginárias.

E quais são as principais modificações que o método fenomenológico sofre ao ser transposto para a pesquisa empírica?

Giorgi (2008, p.396-397) acredita que as principais modificações são:

1. produção de uma descrição concreta e detalhada de experiências específicas, conforme o cotidiano das pessoas;

2. adoção da redução;

3. busca de essências científicas.

De modo geral, essas são as considerações que se colocam quando se discute o assunto, sendo os cinco métodos apresentados os que mais são utilizados pela ciência. Isso revela o quão profunda é a contribuição da fenomenologia.

Nesse sentido, Von Zuben (1989), ao analisar o impacto das ideias fenomenológicas no século XX, afirma que:

Desde o início deste século, um número expressivo de pensadores se deixaram influenciar pelas ideias de Husserl. Muitos as criticaram, outros tantos buscaram nelas impulso e movimento para suas próprias ideias. E mais, a filosofia fenomenológica de Husserl teve seus efeitos na própria metodologia das ciências. (Ibidem, p.148)

Por sua vez, Heidegger (1973), discutindo sobre a questão da contemporaneidade da fenomenologia, pergunta:

E hoje? Parece que o tempo da filosofia fenomenológica passou. Já é julgada como algo passado, que é apenas consignado ainda historiograficamente ao lado de outros movimentos filosóficos. Entretanto, a fenomenologia não é nenhum movimento, naquilo que lhe é mais próprio. Ela é a possibilidade do pensamento - que periodicamente se transforma e somente assim permanece - de corresponder ao apelo do que deve ser pensado. Se a fenomenologia for assim compreendida e guardada, então, pode desaparecer como expressão, para dar lugar à questão do pensamento, cuja manifestação permanece um mistério. (Ibidem, p.499)

Logo, como possibilidade de pensamento, a fenomenologia indica por qual caminho se deve caminhar para avançar às coisas mesmas; ou seja, esclarece sobre aquilo que necessita ser conhecido com clareza. Essa é uma demanda da administração, em geral, e dos estudos organizacionais, em particular: situar sua posição perante a imensidão dos fenômenos que lhe ocorrem cotidianamente, para captar suas essências, de modo a compreendê-los profundamente.

Conforme observa Guerreiro Ramos (1981), a administração e as ciências sociais que a originaram são instrumentos para a legitimação do status quo. Isso ocorre porque as pesquisas se ocupam com o imediatismo dos resultados, adotando uma posição ingênua e irrefletida. Para reverter tal situação, deveriam ser questionadas as práticas e valores vigentes, por meio de uma reflexão crítica. Ademais, existe a questão 
da utilização equivocada que a administração faz de conceitos de outras ciências sociais. Modificando o sentido original, os pesquisadores alteram o significado inicial, muitas vezes, utilizando os conceitos de forma inversa ao sentido inicialmente proposto. Para superar tal questão, a fenomenologia torna-se útil nesse momento, como o próprio autor reconhece em seus escritos.

Assim, uma análise da administração de forma indissociável da filosofia oferece contribuições sobre os fenômenos organizacionais. As contribuições que estudos filosóficos podem oferecer extrapolam a esfera das possibilidades e podem se tornar realidade. A questão é que a filosofia pode, concretamente, modificar o entendimento da realidade humana. Além disso, a fenomenologia se constitui em um importante meio para auxiliar o trabalho dos cientistas das ciências administrativas, devido ao seu caráter constituinte e deflagrador de novas abordagens.

Dessa forma, na sequência, verificar-se-á como tal realidade está se configurando.

Sobre o Uso da Fenomenologia nas Ciências Administrativas: Considerações sobre Pesquisas Realizadas e Possibilidades

A questão da fenomenologia se encontra em ascensão nos estudos organizacionais, revelando que há interesse crescente por parte dos pesquisadores em se chegar à essência dos fenômenos pesquisados. Para ilustrar tal interesse, demonstrar-se-á, a seguir, investigações efetuadas abordando a fenomenologia.

Moreira (2002) observa que há um incremento na utilização do método fenomenológico nas pesquisas em administração, mas os pesquisadores não sabem definir exatamente o que seja fenomenologia. Discute ainda a dificuldade de se transpor um método filosófico para a pesquisa empírica e as adaptações necessárias para que isso ocorra, além de apresentar possíveis variantes que podem ser utilizadas na pesquisa em administração.

Gil (2003) procura analisar a aplicabilidade do método fenomenológico na pesquisa em administração. O autor recorre a Husserl para discutir conceitos fenomenológicos, observando que muitas pesquisas chamadas fenomenológicas não podem ser assim definidas, devido a imprecisões metodológicas dos pesquisadores. Acredita não apenas que o método fenomenológico seja uma promessa para a pesquisa em administração, mas também que o interesse de muitos pesquisadores pelo método decorra da preferência por pesquisas qualitativas, não do reconhecimento de seu alcance metodológico e epistemológico.

Anosike (2008) pesquisa o marketing interno, a partir da abordagem de Giorgi (1985), tecendo importantes considerações sobre o método fenomenológico. Ao final, desvela nove elementos centrais relacionados ao temas da investigação.

Paiva Júnior (2004) analisa o empreendedorismo na ação de empreender, a partir da fenomenologia de Alfred Schütz. O fenômeno empreendedor é compreendido na ótica de dirigentes de empresas de base tecnológica. $\mathrm{O}$ pensamento e a ação empreendedora são fundamentados em seis categorias: na imaginação social, na cultura, na identidade, nas relações de poder, no expertise e na interação social.

Gibson e Hanes (2003) reveem o estado atual da pesquisa fenomenológica em recursos humanos e propõem uma agenda para pesquisas futuras no campo. Apresentam a fenomenologia como uma metodologia interpretativa para a pesquisa na área, essencial para possibilitar uma compreensão mais completa da natureza holística e da complexidade de experiências relevantes à prática desse ramo da administração. 
Thiry-Cherques (2004) afirma que os métodos de raiz fenomenológica são convenientes à ciência da gestão. Partindo da fenomenologia de Husserl, o autor apresenta seus principais conceitos e faz diversas considerações sobre o movimento fenomenológico, discorrendo sobre um programa para aplicação nas pesquisas em administração do método fenomenológico.

Carvalho e Vergara (2002) consideram impossível entender as experiências interativas e as vivências essenciais dos consumidores com os ambientes físicos de serviços valendo-se de procedimentos metodológicos convencionais. Eles apresentam argumentos, procedimentos e formais pelas quais a fenomenologia pode ser uma opção metodológica adequada à pesquisa nesses ambientes.

Ehrich (2005) faz considerações sobre a transposição da filosofia fenomenológica para a pesquisa empírica fenomenológica. Apresenta e discute as ideias do fundador da fenomenologia, Husserl, e afirma que tal metodologia tem muito a oferecer à administração.

Boava e Macedo (2009) esboçam uma teoria tridimensional do empreendedorismo, a partir da fenomenologia de Husserl, Sartre e Heidegger, composta de ação, valor e finalidade.

Há ainda diversos outros autores que fazem uso da fenomenologia, mas os apresentados são necessários e suficientes para demonstrar sua aplicabilidade.

Há de se destacar que os estudos organizacionais apresentam um método fenomenológico próprio. Sanders (1982, p. 356), no clássico artigo Phenomenology: a new way of viewing organizational research, discorre sobre a dificuldade de se encontrar estudos fenomenológicos na pesquisa em administração. Apresenta e discute aspectos da fenomenologia e também um modelo de pesquisa específica para a área, além de tecer considerações sobre a questão paradigmática da ciência e suas relações com o tema. Tal método se estrutura da seguinte maneira:

1. determinação dos limites - o que e quem serão investigados;

2. coleta de dados - efetuado por meio de entrevistas, relatos ou observação participante;

3. análise fenomenológica dos dados - se faz em quatro etapas: a) descrição do fenômeno; b) identificação dos temas e constituintes invariantes; c) desenvolvimento das correlações noéticas/noemáticas (percepção individual da realidade do fenômeno pesquisado); d) estabelecimento de essências.

Tudo isso ocorre por ser uma demanda da área. Uma demanda de novas abordagens para antigos problemas e questões que surgem no cotidiano da prática administrativa; ou seja, uma busca de fundamentação. Por sua vez, toda fundamentação busca o conjunto de princípios que fazem uma realidade, e é isso que os estudos organizacionais procuram. Em outras palavras, busca-se um conjunto de conhecimentos constituintes e invariantes, para se ter um corpo epistêmico. Isso a fenomenologia pode oferecer.

Chauí (2005, p.229-31) observa que a constituição das ciências humanas como ciências específicas consolidou-se a partir das contribuições da fenomenologia, do marxismo e do estruturalismo, que provocaram uma ruptura epistemológica e uma revolução científica no campo das humanidades. Assim, a fenomenologia contribuiu com a questão ao possibilitar que fosse feita a distinção rigorosa entre a essência natureza e a essência homem. Em seguida, permitiu que o homem fosse distinguido em relação a outras essências diversas: o psíquico, o social, o histórico, o cultural. Isto é, foi a fenomenologia que permitiu a delimitação e a definição dos objetos das ciências humanas.

Nos estudos organizacionais, pode-se recorrer à fenomenologia para estudar, por exemplo, os seguintes fenômenos: poder, simbolismo, gênero, etnia, questões socioambientais (inclusive, as econômicas), conhecimento, discursos, o sentido do trabalho, ética, comunicação e relações, tecnicismo, cientificismo, 
organilogismo etc. Isto é, há uma variedade de temáticas em que se pode atingir, fenomenologicamente, as essências invariáveis constituintes. Pois na filosofia fenomenológica já está havendo espaço para isso, pelo fato dela estar se voltando para as atividades culturais, as práticas mundanas. A organização, assim, é um espaço em que se encontram diferentes experiências e pessoas, sendo uma espécie de reprodução da vida cotidiana, e tais pessoas são dotadas de consciência, aspirações, sonhos e problemas.

Portanto, toda organização é dotada de personalidade própria, no sentido de que para ela confluem constituintes variados que podem ser apreendidos por meios fenomenológicos.

Não se busca padrões, respostas generalizantes passíveis de reprodução, mas sim os constituintes essenciais dos fenômenos. Tais constituintes, uma vez esclarecidos, podem contribuir com a área e fazer com que a administração revele aspectos pouco explorados de sua natureza.

Um campo eminentemente praxeológico pode-se revelar também dotado de outros sentidos, não desvelados à primeira vista.

Em suma, a fenomenologia apresenta-se como um meio científico-filosófico de desarraigamento de prática de pesquisa funcionalista-positivista que permeia toda a atividade administrativa. A questão é saber se isso é possível nesta época, em que a ideologia da ciência é dominada pela questão da técnica e pelo modo de produção capitalista.

\section{Considerações finais}

Observou-se neste artigo, no transcurso das exposições apresentadas, uma série de considerações relativas a outra possibilidade de compreensão dos fenômenos administrativos, através de uma descrição propedêutica da fenomenologia e do método fenomenológico, em caráter essencial. Tal estudo foi elaborado fenomenologicamente, o que significa que se buscou descrever a realidade, para atingir-se a essência da questão sobre a fenomenologia e estudos organizacionais.

Por limitações de espaço, não foi possível aprofundar-se nas análises sobre a aplicação da fenomenologia em estudos organizacionais (o que será objeto de estudos vindouros); ou seja, este é o primeiro passo dado no sentido de se estabelecer um conjunto sistemático de investigações fenomenológicas em administração, de cunho epistemológico. Por isso, considerações sobre os sentidos abrangentes de termos próprios da fenomenologia (como, por exemplo, consciência, fenômeno, noema, noésis, constituinte, essência etc.) foram efetuadas de maneira introdutória, não exaustiva.

A ênfase dada para a fenomenologia, em geral, e aos diversos tipos de métodos fenomenológicos, em particular, deveu-se à necessidade de se esclarecer sobre a filosofia que existe nesses temas, para auxiliar os pesquisadores em seu labor diário. Isso se revela importante na discussão realizada sobre os usos do vocábulo fenomenologia por diferentes filósofos ao longo do tempo.

Este estudo também abordou os seis tipos de fenomenologia existentes e as formas pelas quais o campo se desenvolveu. Nesse ínterim, a fenomenologia descritiva representa a origem do movimento fenomenológico e ocupa-se das evidências. Já a realista busca alcançar as essências universais, enquanto a constitutiva vai ao encontro das ciências naturais. Existe ainda a fenomenologia existencial, que discute temas próprios do homem, e a fenomenologia hermenêutica, que considera a interpretação um momento decisivo para a captação dos fenômenos. Por sua vez, a fenomenologia cultural privilegia a vida mundana, tal qual ela se apresenta e se desenvolve. 
No que diz respeito à questão do método, constatou-se que não existe um ou o método fenomenológico. Isso é deveras importante, pois pode resultar em desinformação e confusão para o pesquisador empírico não familiarizado com a filosofia. Contudo, apresentou-se uma série de sete passos relativos aos procedimentos adotados pelos filósofos (espécie de método), o que pode auxiliar os pesquisadores e diminuir a confusão.

$\mathrm{Na}$ exposição apresentada também se verificou a redução, que na verdade são duas (basicamente): a eidética e a fenomenológica. A redução eidética busca, como o nome diz, atingir o eidos, a essência do fenômeno. $\mathrm{O}$ modo de se fazê-la foi ilustrado com um conjunto de cinco passos. Já a redução fenomenológica limita o conhecimento ao fenômeno da experiência de consciência. O modo de fazê-la consiste em desconsiderar o mundo real, colocando-o entre parênteses; ou seja, há uma suspensão do juízo.

Tais reduções são vitais para retirar o homem de sua atitude natural e fazê-lo um ser reflexivo. Chama-se atitude natural o modo próprio de ser do homem: os termos e o modo pelo qual ele percebe, interpreta e age no mundo em que vive, sendo, ingênuo.

Há de se salientar que tanto o método como a redução tornam-se questões-chave em qualquer discussão sobre fenomenologia, pois constituem sua fundamentação, devendo ser observado que delas deriva o próprio entendimento do que seja fenomenologia. Entender seus significados e implicações resulta em compreender, de fato, o que a fenomenologia representa (tanto em sua concretude como em suas infinitas possibilidades).

Outro assunto abordado foi a transposição do método fenomenológico do campo filosófico para o campo da pesquisa empírica. A discussão foi a mais extensa, em função do imperativo de se esclarecer as adaptações sofridas para a concretização de tal empreitada.

Foram apresentados cinco diferentes métodos, com a descrição de suas etapas. Isso foi útil para exemplificar as diferentes maneiras como a ciência se apropriou do conhecimento filosófico. Ademais, foi verificado que tais métodos podem fazer com que os pesquisadores os utilizem de forma equivocada, por não conhecerem as bases filosóficas dos mesmos. Surge então um questionamento: até que ponto as pesquisas empíricas são fenomenológicas? Para responder a tal pergunta, o artigo esclarece quais os meios pelos quais essa verificação pode ser feita, os quais passam por uma análise de quatro itens: consciência intencional, utilização da redução, descrição e busca pela essência.

O último assunto abordado está relacionado à utilização da fenomenologia no contexto da administração.

A título de ilustração, foram apresentados diversos estudos cujo tema é a fenomenologia aplicada à pesquisa organizacional como recurso capaz de trazer ao campo administrativo importantes considerações. Também foi feita a exposição de um método fenomenológico empírico, específico da área de estudos organizacionais, composto de três etapas, as quais foram aqui descritas.

Ainda nessa linha, sugeriu-se que a fenomenologia pode ser utilizada na investigação de fenômenos organizacionais ligados aos seguintes temas: poder, simbolismo, gênero, etnia, questões socioambientais (inclusive, as econômicas), conhecimento, discursos, o sentido do trabalho, ética, comunicação e relações, tecnicismo, cientificismo, organilogismo etc.

Dessa maneira, a temática neste artigo foi situada, sendo preciso agora avançar-se em direção a outras possibilidades. Isso é fundamental.

Qual o motivo para se fazer isso? Simples; a razão para isso é o fenômeno. Pois, como observado, existe uma questão ideológica muito proeminente na administração, inerente ao próprio modo de produção capitalista. Assim, tal aspecto torna-se um viés nas pesquisas. A teoria crítica, por exemplo, observa e considera essa realidade. Entretanto, as pesquisas não fenomenológicas não lidam com o fenômeno da fenomenologia e consideram a realidade de uma forma diferente. 
A fenomenologia contribui para esse debate, pois ela possibilita que os fenômenos falem por si mesmos. Não é possível que o pesquisador fale por eles. Ao se mostrar como é, a realidade é desvelada e a essência é atingida. Ao se atingir a essência de um fenômeno, pode-se seguir adiante na compreensão de constituintes invariantes e se estabelecer teorias sobre o que se está pesquisando.

Não se trata aqui de teorias empíricas, tais quais são encontradas na ciência, mas teorias filosóficas, especulativas e que geralmente a própria ciência faz uso posterior (por exemplo, a própria fenomenologia).

Ressalta-se que a fenomenologia não é a portadora da razão inequívoca (pelo contrário, ela mesma constituise num emaranhado de contradições). Ela representa, antes de tudo, um método de acesso ao conhecimento peculiar. Em outros termos, um modo diferente de compreender os significados esquecidos, ocultos e nebulosos. Uma possibilidade. Possibilidade de se atingir o núcleo do que se pesquisa, a essência.

Sinteticamente, pode-se concluir que os estudos organizacionais experimentarão um ganho de ordem epistêmico-ontolológica ao incluir em seu rol de metodologias a abordagem fenomenológica, em função da grandeza de novas análises que podem ser feitas. Para tal, os filósofos poderiam contribuir de forma decisiva, pela capacidade que possuem para elaborar investigações especulativas ricas e férteis. O convite e o desafio estão propostos.

\section{Referências}

ABBAGNANO, N. História da filosofia. Portugal: Editorial Presença, 1993. v.XIV.

ANOSIKE, U. P. A phenomenological exploration of the domain and structure of internal marketing. Tese (Doutorado em Filosofia) - University of Wolverhampton, Wolverhampton, 2008.

BOAVA, D. L. T.; MACEDO, F. M. F. Esboço para uma teoria tridimensional do empreendedorismo. In: ENCONTRO DA ASSOCIAÇÃO NACIONAL DOS PROGRAMAS DE PÓS-GRADUAÇÃO E PESQUISA EM ADMINISTRAÇÃO - EnANPAD, 33., 2009, São Paulo. Anais... Salvador: Anpad, 2009.

BOCHENSKI, J. M. Los metodos actuales del pensamiento. Madrid: Rialp, 1971.

CARVALHO, J. L.; VERGARA, S. C. A fenomenologia e a pesquisa dos espaços de serviços. RAE - Revista de Administração de Empresas, v.42, n.3, p. 78-91, 2002.

CHAUÍ, M. Convite à filosofia. Ática: São Paulo, 2005.

COLAIZZI, P. F. Psychological research as the phenomenologist views it. In: VALLE, R. S.; KING, M. Existential phenomenological alternatives for psychology. New York: Oxford University Press, 1978.

EHRICH, L. Revisiting phenomenology: it's potential for management research. In: PROCEEDINGS CHALLENGES or organisations in global markets. British Academy of Management Conference. Said Business School, Oxford University, 2005.

EMBREE, L. et al. Encyclopedia of phenomenology. Dordrecht: Kluwer, 1997. 2001.

. The continuation of phenomenology: a fifth period? Indo-Pacific Journal of Phenomenology, v.1, n.1, p.1-9,

Continuing husserlian phenomenology. 2005. Husserl archives in memory of Alfred Schütz. Disponível em:

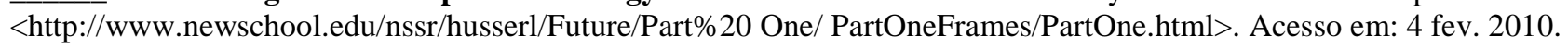


FICHTE, J. G. Wissenschaftlehre. In: WRIGHT, W. W. The science of knowing: J. G. Fichte's 1804 lectures on the Wissenschaftslehre. Albany: State University of New York, 2005.

GIBSON, S. K.; HANES, L. A. The contribution of phenomenology to HRD research. Human Resource Development Review, v.2, n.2, p.181-205, 2003.

GIL, A. C. O método fenomenológico na pesquisa em administração. Caderno de Pesquisa Pós-Graduação Imes, São Caetano do Sul,v.4, n.8, p.33-42, 2003.

GILES, T. R. História do existencialismo e da fenomenologia. São Paulo: EPU, 1989.

GIORGI, A. A psicologia como ciência humana: uma abordagem fenomenológica, Belo Horizonte: Interlivros, 1978.

. Phenomenology and psychological research. Pittsburg: Duquesne University Press, 1985. p.75-82, 2005.

The phenomenological movement and research in the human sciences. Nursing science quarterly, v.18, n.1,

Sobre o método fenomenológico utilizado como modo de pesquisa qualitativa nas ciências humanas: teoria, prática e avaliação. In: POUPART, J. et al. A pesquisa qualitativa: enfoques epistemológicos e metodológicos. Petrópolis: Vozes, 2008.

GIORGI, A.; GIORGI, B. The descriptive phenomenological psychological method. In: CAMIC, P. M.; RHODES, J. E.; YARDLEY, L. Qualitative research in psychology: expanding perspectives in methodology and design. Washington, DC: American Psychological Association, 2003.

GUERREIRO RAMOS, A. A nova ciência das organizações: uma reconceituação da riqueza das nações. Rio de Janeiro: FGV 1981.

HEGEL, F. G. W. Phänomenologie des geistes. 1807. Disponível em <http://books.google. com/books?id=2b4IAAAAQAAJ>. Acesso em: 4 fev. 2010.

HEIDEGGER, M. Meu caminho para a fenomenologia. São Paulo: Abril Cultural, 1973. (Coleção Os Pensadores).

HUSSERL, E. Investigações lógicas: sexta investigação (elementos de uma elucidação fenomenológica do conhecimento). São Paulo: Nova Cultural, 1988.

. A ideia da fenomenologia. Portugal: Edições 70, 1990.

. Ser e tempo. Petrópolis: Vozes, 1999.

Investigaciones lógicas 1. Madrid: Alianza Editorial, 1999a.

Investigaciones lógicas 2. Madrid: Alianza Editorial, $1999 \mathrm{~b}$.

Ideias para uma fenomenologia pura e para uma filosofia fenomenológica: introdução geral à fenomenologia pura. Aparecida: Ideias \& Letras, 2006.

KANT, I. Letter to J. H. Lambert. September 2, 1770. In: ZWEIG, A. Immanuel Kant: correspondence. New York: Cambridge University Press, 1999a.

.De mundi sensibilis atque intelligibilis forma et principiis. 1770. Disponível em <http://ia341302.us.archive.org/2/items/cu31924029022329/cu31924029022329.pdf> Acesso em: 4 fev. 2010.

Letter to MARCUS HERZ. February 21, 1772. In: ZWEIG, A. Immanuel Kant: Correspondence. New York: Cambridge University Press, 1999b. 
- Critique of pure reason. 1781. Disponível em <http://ia341330.us.archive. org/1/items/cu31924092291065/cu31924092291065.pdf> Acesso em: 4 fev. 2010.

. Metaphysical foundations of natural science. 1786 . Disponível em <http://ia341324.us.archive.org/3/items/cu31924029022213/cu31924029022213.pdf>. Acesso em: 4 fev. 2010.

LAMBERT, J. H. Neues Organon oder Gedanken über die Erforschung und Bezeichnung des Wahren. 1764. Disponível em: <http://books.google.com/books?id=dvMNAAAAYAAJ>. Acesso em: 4 fev. 2010.

MORA, J. F. La filosofía en el mundo de hoy. Madrid: Revista de Occidente, 1963.

MOREIRA, D. A. Pesquisa em administração: origens, usos e variantes do método fenomenológico. In: ENCONTRO DA ASSOCIAÇÃO NACIONAL DOS PROGRAMAS DE PÓS-GRADUAÇÃO E PESQUISA EM ADMINISTRAÇÃO - EnANPAD, 26., 2002, Salvador. Anais... Salvador: Anpad, 2002.

MOUSTAKAS, C. Phenomenological research methods. Thousand Oaks: Sage Publications, 1994.

OETINGER, F. C. Die Philosophie der Alten wiederkommend in der güldenen Zeit. 1762. Disponível em <http://books.google.com/books?id=3Wc6AAAAcAAJ> Acesso em: 4 fev. 2010.

PAIVA JÚNIOR, F. G. O empreendedorismo na ação de empreender: uma análise sob o enfoque da fenomenologia sociológica de Alfred Schütz. Tese (Doutorado em Administração) - UFMG, Belo Horizonte, 2004.

SANDERS, P. Phenomenology: a new way of viewing organizational research. Academy of management review, v.7, n.3, p.353-360, 1982.

SPIEGELBERG, H. The phenomenological movement. The Hague: Martinus Nijhoff, 1982.

THIRY-CHERQUES, H. R. Programa para aplicação às ciências da gestão de um método de caráter fenomenológico. In: VIEIRA, M. M. F; ZOUAIN, D. M. Pesquisa qualitativa em administração. Rio de Janeiro: FGV, 2004.

VAN KAAM, A. L. Phenomenal analysis exemplified by a study of the experience of 'really feeling understood'. Journal of Individual Psychology, v.15, n.1, p.66-72, 1959.

Existential foundations of psychology. Pittsburgh: Duquesne University Press, 1966.

VAN MANEN, M. Researching lived experience: human science for an action sensitive pedagogy. Albany: State University of New York, 1990.

VON ZUBEN, N. A. A fenomenologia em questão: desafios de um projeto. In: CARVALHO, M. C. M. Paradigmas filosóficos da atualidade. Campinas: Papirus, 1989. 